\title{
Pattern of drug use among preterm neonates: results from an Italian neonatal intensive care unit
}

\author{
A. Girardi ${ }^{1}$, S. Galletti ${ }^{1}$, E. Raschi ${ }^{1}$, A. Koci ${ }^{1}$, E. Poluzzi ${ }^{1}$, G. Faldella ${ }^{1}$ and F. De Ponti, ${ }^{1 *}$ (D)
}

\begin{abstract}
Background: Drug use in preterm neonates admitted to Neonatal Intensive Care Unit (NICU) has been investigated, so far, in terms of unauthorized or off-label use; very little is known on the use of combinations of different active substances, which is frequently required in this population (prophylaxis of infections, treatment of concomitant diseases). The aim of this study was to describe the most common patterns of drug use in an Italian NICU, focusing on those with nephrotoxic potential.
\end{abstract}

Methods: Medical records of preterm neonates (<37 weeks of gestational age) weighing less than 1,500 $\mathrm{g}$ at birth and admitted to an Italian NICU were scrutinized in a 3-year retrospective investigation. Analysis included drug exposure, duration of therapies, co-administration of drugs with potential renal side effects; also daily protein supplement was calculated from parenteral nutrition.

Results: A cohort of 159 preterm neonates was selected; 68 were born weighing less than 1,000 g (extremely low birth weight infants, ELBW, Group A), 91 weighed between 1,000 and 1,500 g at birth (Group B). Compared to Group B, neonates of Group A were more likely to receive pharmacological treatments: the most used drugs were antibiotics (especially ampicillin and amikacin, $p=.07$ and $p<.001$, respectively), antifungals (especially fluconazole, $p<.001$ ), and diuretics (especially furosemide, $p<.001$ ). Analysis of co-administration of drugs with potential nephrotoxicity showed ampicillin and amikacin as the most reported combination (94.1\% of Group A and 31.9\% of Group B), the combination of furosemide with antibacterials (ampicillin or amikacin) was also frequently reported, with average period of combination shorter than 2 days.

Conclusions: ELBW infants were exposed to a higher number of drugs compared to other neonates and were more likely to receive associations of drugs with nephrotoxic potential (e.g. furosemide and amikacin), though only for short cycles. Further studies should evaluate the safety profile (especially potential renal side effects) related to most commonly used combinations.

Keywords: Neonatal intensive care unit, Preterm neonates, Drug use, Nephrotoxicity

\section{Background}

Neonates, especially those born prematurely, are characterized by several specific pathological conditions and require the administration of several concomitant pharmacological treatments. For instance, in the first postnatal period, neonatologists often have to manage respiratory distress syndrome, patent ductus arteriosus (PDA), necrotizing

\footnotetext{
*Correspondence: fabrizio.deponti@unibo.it

'Department of Medical and Surgical Sciences, University of Bologna 40138, Bologna, Italy

${ }^{2}$ Present Address: Department of Medical and Surgical Sciences, University of Bologna, via Irnerio 48 40126, Bologna, Italy
}

enterocolitis (NEC) and other infections [1]. At present, very little is known on the actual use of combination of drugs in neonatal intensive care settings and their safety; studies investigating drug use in the neonatal population usually focused on single active substances and their status in terms of unauthorized or off-label use [2-5]. The evidence gathered so far however highlighted increased susceptibility of babies to drug-related toxicity (especially, renal damage [2]).

The issue of evidence-based pharmacological treatment among neonates is unsolved, especially because of 
known difficulties in performing clinical trials in this population. Also observational research by collecting "real-world" data from Neonatal Intensive Care Units (NICUs) is challenging because of potential heterogeneity of patients enrolled in multicenter studies. Almost all medications are actually used off-label in newborns (especially if preterm); some exceptions are represented by some antibacterials, for instance amikacin. Therefore, National and Regional guidelines (in Italy, as well as in most Western Countries, e.g. British National Formulary for Children) have been created on the basis of consolidated clinical use of off-label drugs in pediatrics, providing information for neonatal and pediatric units. Moreover, the Paediatric Committee of the European Medicines Agency periodically identifies a list of active substances for which data on efficacy and side effects in the pediatric population (including neonates) are requested [6].

Thus, evidence from clinical practice is particularly useful not only for the assessment of the risk-benefit profile of drugs in neonates, but also for the opportunity to add recommendations in this population and to gain insight into relevant unmet clinical needs.

The present study aims at: (1) describing the use of drugs among preterm neonates, especially in terms of co-administrations, and (2) focusing on the use of agents with nephrotoxic potential.

\section{Methods}

\section{Study Cohort}

The study was conducted retrospectively in the tertiarylevel NICU of the "S. Orsola-Malpighi" Hospital in Bologna (Northern Italy) after notification to the Institutional Ethics Committee (Comitato Etico Policlinico S.Orsola-Malpighi, $34 / 2015 / \mathrm{U} / \mathrm{Oss})$. Newborns were included in the study on the basis of the following criteria: born at the "S. Orsola-Malpighi" Hospital between January 01, 2009 and December 31, 2011 and admitted to the NICU of the same hospital; gestational age $<37$ weeks and weight at birth $\leq$ $1,500 \mathrm{~g}$. Patients who died within the first $48 \mathrm{~h}$ after birth were excluded.

\section{Data collection}

For each neonate, medical records were scrutinized to collect data on twin birth, pathological conditions at birth and during the hospitalization, duration of hospitalization, type of drug prescribed classified according to the anatomical therapeutic chemical (ATC) system (WHO Collaborating Centre For Drug Statistics Methodology, Guidelines for ATC classification and DDD assignment 2009. Oslo, 2008), the starting age and the duration of therapy. Active substances with potential renal side effects were identified according to published data [2]: antibacterials (ampicillin, piperacillin, vancomycin, amikacin), antifungals (amphotericin B), loop diuretics (furosemide), non-steroidal anti-inflammatory drugs (indomethacin, ibuprofen), and paracetamol (acetaminophen). All data acquired from medical records were stored in an electronic database.

\section{Statistical analysis}

Neonates were classified into two groups according to birth weight: Group A neonates weighing $\leq 1,000 \mathrm{~g}$ at birth (extremely low birth weight, ELBW) and Group B neonates weighing $>1,000 \mathrm{~g}$ and $\leq 1,500 \mathrm{~g}$ at birth.

Analysis of drug use was performed with Access ${ }^{\circ}$ software and included: (a) exposure, defined as the number of unique active substances reported for each neonate, (b) courses, defined as the number of times a unique active substance was reported for a single patient with a specific start date (the analysis of courses shows if a pharmacological treatment was chosen more than once during hospitalization), (c) courses per exposure (number of times neonates were exposed to more than one course of a specific drug) and (d) duration per courses (when a unique active substance was administered more than once for a single patient, exposure time for each course was calculated). Co-administrations of drugs were calculated on the basis of each neonate daily therapy and assembling together treatments used in the same period of time (Fig. 1). For the estimation of protein intake, we recorded the daily amount and duration of protein administration included in the parenteral nutrition. Differences between groups were evaluated using the Chi-square test and Fisher's exact test; statistical significance was defined for $p \leq 0.05$.

\section{Results}

Among all preterm neonates admitted to NICU in the study period, medical records were available for 159 patients: 68 neonates weighing less than $1,000 \mathrm{~g}$ at birth (Group A), and 91 neonates weighing $>1,000 \mathrm{~g}$

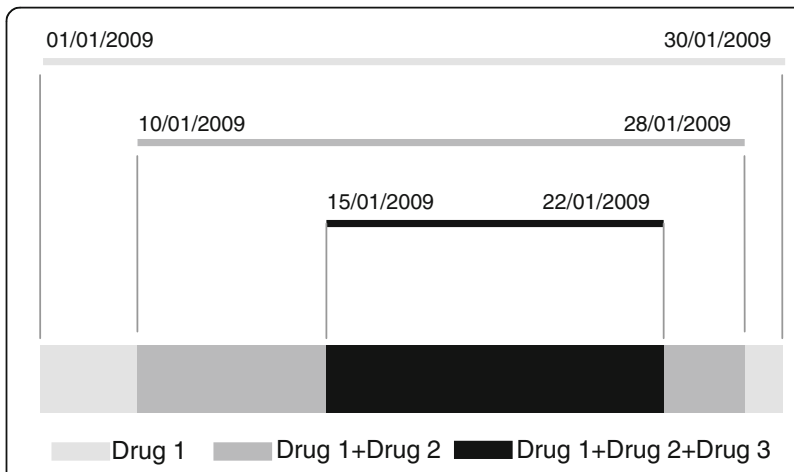

Fig. 1 Schematic representation of our approach to describe co-administrations of drugs: for instance, when a second drug was added to drug 1, we recorded this exposure as drug $1+$ drug2 and considered the relevant co-administration time-period 
and $\leq 1,500 \mathrm{~g}$ (Group B). Characteristics of the two populations are presented in Table 1. All neonates of Group A needed pharmacological treatments and they

Table 1 Characteristics of the study population and pharmacological treatment

\begin{tabular}{|c|c|c|}
\hline & GROUP A & GROUP B \\
\hline & $N=68$ & $N=91$ \\
\hline \multicolumn{3}{|l|}{ Gesational age, weeks } \\
\hline Average & 26 & 30 \\
\hline Range & $22-32$ & $27-36$ \\
\hline \multicolumn{3}{|l|}{ Birth weight, g } \\
\hline Average & 739 & 1309 \\
\hline Range & $380-1000$ & $1023-1532$ \\
\hline \multicolumn{3}{|l|}{ Discharge age, days } \\
\hline Average & 57 & 23 \\
\hline Range & $2-218$ & $1-175$ \\
\hline Singleton birth, \% & 77.9 & 71.4 \\
\hline \multicolumn{3}{|l|}{ Outcome, \% } \\
\hline Death & 17.7 & 3.3 \\
\hline Transfer & 4.4 & 5.5 \\
\hline Home & 77.9 & 91.2 \\
\hline \multicolumn{3}{|l|}{ Diseases, \% } \\
\hline Respiratory distress syndrome & 82.4 & 86.8 \\
\hline Anemia & 75.0 & 35.2 \\
\hline Hyperbilirubinemia & 70.6 & 93.4 \\
\hline Patent ductus arteriosus & 52.9 & 42.9 \\
\hline Sepsis & 38.2 & 11.0 \\
\hline Hyaline membrane disease & 27.9 & 5.5 \\
\hline Intrauterine growth restriction & 23.5 & 17.6 \\
\hline Central nervous system impairment & 22.1 & 8.8 \\
\hline Necrotizing enterocolitis & 13.2 & 5.5 \\
\hline Cardiac malformation & 11.8 & 15.4 \\
\hline Pharmacological treatments, \% & 100 & 95.7 \\
\hline \multicolumn{3}{|l|}{ Number of drugs, $\%$} \\
\hline$\leq 5$ & 0 & 17.6 \\
\hline $5-10$ & 4.4 & 40.7 \\
\hline $11-20$ & 51.5 & 33.0 \\
\hline$>20$ & 44.1 & 4.4 \\
\hline Combination of drugs, $\%$ & 100 & 93.4 \\
\hline \multicolumn{3}{|l|}{ Route of administration, \% } \\
\hline Drugs for systemic use & 100 & 96.7 \\
\hline Drugs for topical use & 82.4 & 57.1 \\
\hline Drugs for ophthalmic use & 44.1 & 14.3 \\
\hline $\begin{array}{l}\text { Exposure to at least one drug with } \\
\text { potential renal toxicity }{ }^{a}, \%\end{array}$ & 100 & 93.4 \\
\hline
\end{tabular}

received a higher number of different active substances compared to Group B (Table 1): 95,6\% of Group A and 37,4\% of Group B received more than 10 different drugs throughout their stay in NICU; moreover, all ELBW infants and 93,4\% of Group B were exposed to associations.

All neonates of Group A and 93.4\% of Group B were exposed to at least one drug with potential renal side effect. At birth, all neonates received a single administration of ophthalmic antibiotic (tobramycin) and vitamin $\mathrm{K}$; frequency of exposure to drugs, duration and courses of pharmacological treatments in both groups are shown in Table 2 and Table 3. In the first days of life, neonates were especially exposed to antibacterials, in particular ampicillin and amikacin, and antifungal agents, mainly fluconazole. In case another antibacterial was needed after the end of early treatment with ampicillin or amikacin, the most prescribed active substances in both groups were piperacillin, vancomycin, clarithromycin and erythromycin, and they were started on average three weeks after birth. Neonates weighing less than $1,500 \mathrm{~g}$ at birth were more likely to receive antibacterials (with the exception of ampicillin) and antifungals compared to Group B (Table 4); moreover, in neonates of Group A, treatment with anti-infective agents lasted more than three times as long as in Group B.

Caffeine was widely used, especially among neonates of Group A compared to Group B, as well as lung surfactants, whose main indications are prevention and treatment of respiratory distress syndrome; only for few cases, the additional administration of doxapram was requested. Neonates of Group A were more likely to receive diuretics compared to Group B; moreover, neonates of Group A treated with furosemide received at least two different administrations, with an average exposure duration of 12 days.

Almost all neonates of Group A were exposed to a combination of drugs with nephrotoxic potential; the most commonly reported combination in both groups was ampicillin and amikacin $(94.1 \%$ Group A and $31.9 \%$ Group B), also the association of furosemide with ampicillin or amikacin was frequently reported; the average period of co-administration did not exceed 2 days, with the exception of piperacillin and vancomycin in Group B (Table 5). Notably, some of the investigated combinations, such as ibuprofen with amikacin, and indomethacin with amikacin, were not prescribed.

Parenteral nutrition were enriched with proteins in 67/69 cases of Group A and 83/91 cases of Group B; no significant differences were shown for dosages, whereas the overall exposure period in Group A was twice as long as in Group B (Table 6). 
Table 2 Most commonly reported active substances in Group A

\begin{tabular}{|c|c|c|c|c|c|}
\hline Active substance & Exposure $(N=68)$ & $\%$ (tot. 100) & Courses & Courses/exposure & Duration per course, $\mathrm{d}$ (average) \\
\hline Ampicillin $^{a}$ & 66 & 97.1 & 66 & - & - \\
\hline Amikacin $^{a}$ & 66 & 97.1 & 76 & 1.2 & 6 \\
\hline Caffeine & 65 & 95.6 & 76 & 1.2 & 35 \\
\hline Fluconazole & 63 & 92.6 & 83 & 1.3 & 25 \\
\hline Calcitriol & 60 & 88.2 & 74 & 1.2 & 39 \\
\hline Furosemide ${ }^{a}$ & 49 & 72.1 & 106 & 2.2 & 6 \\
\hline Fentanyl & 45 & 66.2 & 84 & 1.9 & 8 \\
\hline Hydrochlorothiazide & 34 & 50.0 & 50 & 1.5 & 31 \\
\hline Spironolactone & 34 & 50.0 & 51 & 1.5 & 30 \\
\hline Piperacillin and enzyme inhibitor ${ }^{a}$ & 32 & 47.1 & 43 & 1.3 & 9 \\
\hline Lung surfactant - natural phospholipids & 31 & 45.6 & 34 & 1.1 & 3 \\
\hline Dopamine & 30 & 44.1 & 38 & 1.3 & 9 \\
\hline Metronidazole & 27 & 39.7 & 30 & 1.1 & 11 \\
\hline Calcium folinate & 26 & 38.2 & 27 & 1.0 & 35 \\
\hline Tobramycin & 26 & 38.2 & 35 & 1.3 & 6 \\
\hline Folic acid & 25 & 36.8 & 28 & 1.1 & 31 \\
\hline Dobutamine & 25 & 36.8 & 32 & 1.6 & 6 \\
\hline $\begin{array}{l}\text { Immunoglobulins, normal human, for } \\
\text { intravascular administration }\end{array}$ & 24 & 35.3 & 30 & 1.3 & 3 \\
\hline Vancomycin $^{a}$ & 24 & 35.3 & 37 & 1.3 & 9 \\
\hline Heparinoids for topical use & 23 & 33.8 & 30 & 1.5 & 4 \\
\hline Ibuprofen ${ }^{a}$ & 22 & 32.4 & 22 & - & - \\
\hline Ranitidine & 21 & 30.9 & 22 & 1.1 & 24 \\
\hline Filgrastim & 21 & 30.9 & 26 & 1.2 & 1 \\
\hline Clarithromycin & 20 & 29.4 & 24 & 1.2 & 13 \\
\hline Dexamethasone & 19 & 27.9 & 36 & 1.9 & 12 \\
\hline Calcifediol & 18 & 26.5 & 22 & 1.2 & 32 \\
\hline Atropine & 17 & 25.0 & 19 & 1.1 & 1 \\
\hline Albumin & 16 & 23.5 & 23 & 1.4 & 1 \\
\hline Betamethasone & 14 & 20.6 & 17 & 1.2 & 6 \\
\hline Erythromycin ethylsuccinate & 13 & 19.1 & 13 & - & - \\
\hline Lorazepam & 12 & 17.6 & 23 & 1.9 & 1 \\
\hline Doxapram & 12 & 17.6 & 15 & 1.3 & 12 \\
\hline Phytomenadione & 11 & 16.2 & 13 & 1.2 & 17 \\
\hline Oxacillin & 11 & 16.2 & 13 & 1.2 & 8 \\
\hline Paracetamol (Acetaminophen) ${ }^{\mathrm{a}}$ & 11 & 16.2 & 19 & 1.7 & 6 \\
\hline Beclometasone & 11 & 16.2 & 13 & 1.1 & 11 \\
\hline Ferrous sulfate & 10 & 14.7 & 11 & 1.1 & 16 \\
\hline Amphotericin $\mathrm{B}^{\mathrm{a}}$ & 9 & 13.2 & 10 & 1.6 & 18 \\
\hline Midazolam & 9 & 13.2 & 14 & 1.1 & 10 \\
\hline Insulin (human) & 9 & 13.2 & 10 & 1.6 & 3 \\
\hline Antacids with sodium bicarbonate & 7 & 10.3 & 11 & 1.3 & 4 \\
\hline Glyceryl trinitrate & 7 & 10.3 & 7 & - & - \\
\hline Phenobarbital & 6 & 8.8 & 6 & - & - \\
\hline
\end{tabular}


Table 2 Most commonly reported active substances in Group A (Continued)

\begin{tabular}{|c|c|c|c|c|c|}
\hline Ceftazidime & 6 & 8.8 & 9 & 1.5 & 14 \\
\hline Mupirocin & 6 & 8.8 & 8 & 1.3 & 4 \\
\hline Morphine & 5 & 7.4 & 7 & 1.4 & 20 \\
\hline Hydrocortisone & 4 & 5.9 & 5 & 1.3 & 8 \\
\hline Calcium levofolinate & 4 & 5.9 & 4 & - & - \\
\hline Erythromycin & 4 & 5.9 & 6 & 1.5 & 14 \\
\hline Naloxone & 4 & 5.9 & 4 & - & - \\
\hline Epinephrine & 3 & 4.4 & 3 & - & - \\
\hline Indometacin $^{a}$ & 3 & 4.4 & 3 & - & - \\
\hline Epoprostenol & 3 & 4.4 & 6 & 2.0 & 5 \\
\hline Linezolid & 3 & 4.4 & 3 & - & - \\
\hline
\end{tabular}

Birth weight $\leq 1000 \mathrm{~g}$; frequency $>2 ;{ }^{\text {adrugs }}$ with potential renal side effects [2]

\section{Discussion}

\section{Drug use and combination}

In the present study, we described the current medication use in an Italian NICU and the combination of drugs: almost all neonates admitted to NICU needed a combination of drugs, especially ELBW neonates. Combination of drugs with potential nephrotoxicity regarded antibacterials and furosemide, and their combination did not exceed 2.5 days.

Most preterm newborns received more than 10 drugs during their stay in NICU, with large differences between ELBW and the others. The most commonly used drugs were antimicrobials, especially ampicillin and amikacin, which were usually co-administered in ELBW for prophylactic purposes starting from the first postnatal day. Also furosemide was frequently used, usually starting later, in case of specific cardio-vascular impairment. For all these three medications, potential nephrotoxicity is well known. Apart from ampicillin and amikacin, also combinations with caffeine, used to prevent apnea, and with fluconazole were frequently found.

The high number of different pharmacological treatments used among preterm neonates in the present investigation is likely to be related to a dual need: to preserve vital status of those particularly frail babies through preventive care therapies, and to treat specific pathological conditions.

The higher number of drugs received by ELBW is driven by the fact that these patients are more likely to suffer from concomitant diseases (especially sepsis) requiring intensive prophylaxis. Prevention of neonatal infections is a clinical priority for neonatologists, as recognized in local protocols, because early and late onset neonatal sepsis are identified as a major cause of mortality and are correlated to neurodevelopmental impairment in the first years of life [7, 8], again especially in ELBW [9]. In the present study, apart from the use of specific antimicrobials early after birth, the use of other antibacterials during hospitalization was frequent, meaning a high incidence of suspected lateonset infections (e.g., almost a half of ELBW received piperacillin). Metronidazole should be separately discussed because of its main indication in NEC treatment; as a consequence, ELBW patients were more exposed to metronidazole as they were more likely to suffer from this pathological condition.

Our results on most used classes of drugs (antimicrobials, cardiovascular agents, analgesics and respiratory drugs) are in accordance to other studies investigating the profile of drug use in NICUs, performed in other Western Countries [5, 10-12].

As regards antibiotic choice, our findings are comparable to other Italian NICUs [3, 13], but differ from other Countries [10, 11, 14, 15]. Inter-Country and inter-centre variability in antibiotic choice, dose regimen and intervals in NICUs is commonly reported worldwide [16-18] and a number of factors may explain this difference: (a) the lack of clinical trials performed in this population resulted in deficiency of international guidelines, (b) clinician's attitude and hospital policy may also play an important role in both the choice of active substances and the pattern of antibiotic use, (c) moreover, the local epidemiology of bacterial infection is an essential factor, as well as previous maternal infections.

While the choice of antibacterial agents is still debated, the use of fluconazole among newborns as antifungal prophylaxis is widely acknowledged because of its general safety and proven efficacy for the prevention of invasive candidiasis [19-22].

\section{Drugs with potential renal side effects}

Renal damage onset, particularly acute kidney injury, is common among preterm neonates and correlates with high mortality rate [23, 24]. Among factors that can mitigate this risk, the short-term administration of drugs 
Table 3 Most commonly reported active substances in Group B

\begin{tabular}{|c|c|c|c|c|c|}
\hline Active substance & Exposure $(N=91)$ & $\%(100)$ & Courses & Courses/exposure & Duration per course, $d$ (average) \\
\hline Ampicillin $^{a}$ & 78 & 85.7 & 79 & 1.0 & 5 \\
\hline Caffeine & 69 & 75.8 & 70 & 1.0 & 26 \\
\hline Calcitriol & 61 & 67.0 & 65 & 1.1 & 19 \\
\hline Fluconazole & 45 & 49.5 & 50 & 1.1 & 16 \\
\hline Lung surfactant - natural phospholipids & 34 & 37.4 & 34 & - & - \\
\hline Fentanyl & 32 & 35.2 & 36 & 1.1 & 7 \\
\hline Amikacin $^{a}$ & 32 & 35.2 & 33 & 1.0 & 4 \\
\hline Calcifediol & 25 & 27.5 & 27 & 1.1 & 18 \\
\hline Furosemide $^{a}$ & 23 & 25.3 & 32 & 1.4 & 8 \\
\hline Atropine & 22 & 24.2 & 22 & - & - \\
\hline Folic acid & 16 & 17.6 & 18 & 1.1 & 11 \\
\hline Calcium folinate & 13 & 14.3 & 14 & 1.1 & 15 \\
\hline Vancomycin $^{a}$ & 13 & 14.3 & 16 & 1.2 & 10 \\
\hline Heparinoids for topical use & 12 & 13.2 & 12 & - & - \\
\hline Piperacillin and enzyme inhibitor ${ }^{a}$ & 11 & 12.1 & 13 & 1.2 & 10 \\
\hline Dopamine & 11 & 12.1 & 13 & 1.2 & 6 \\
\hline Ibuprofen ${ }^{a}$ & 11 & 12.1 & 11 & - & - \\
\hline Filgrastim & 10 & 11.0 & 11 & 1.1 & 1 \\
\hline Tobramycin & 9 & 9.9 & 10 & 1.1 & 4 \\
\hline Ranitidine & 8 & 8.8 & 10 & 1.3 & 21 \\
\hline $\begin{array}{l}\text { Immunoglobulins, normal human, } \\
\text { for intravascular administration }\end{array}$ & 8 & 8.8 & 8 & - & - \\
\hline Hydrochlorothiazide & 8 & 8.8 & 8 & - & - \\
\hline Spironolactone & 8 & 8.8 & 8 & - & - \\
\hline Lorazepam & 8 & 8.8 & 15 & 1.9 & 3 \\
\hline Paracetamol (Acetaminophen) ${ }^{a}$ & 7 & 7.7 & 12 & 1.7 & 4 \\
\hline Metronidazole & 7 & 7.7 & 8 & 1.1 & 8 \\
\hline Ferrous sulfate & 7 & 7.7 & 7 & - & - \\
\hline Piperacillin ${ }^{a}$ & 7 & 7.7 & 7 & - & - \\
\hline Doxapram & 6 & 6.6 & 8 & 1.3 & 11 \\
\hline Ceftazidime & 6 & 6.6 & 8 & 1.3 & 11 \\
\hline Mupirocin & 6 & 6.6 & 6 & - & - \\
\hline Alginic acid & 6 & 6.6 & 8 & 1.3 & 12 \\
\hline Glyceryl trinitrate & 5 & 5.5 & 5 & - & - \\
\hline Claritromycin & 5 & 5.5 & 5 & - & - \\
\hline Dobutamine & 5 & 5.5 & 6 & 1.2 & 9 \\
\hline Naloxone & 4 & 4.4 & 4 & - & - \\
\hline Midazolam & 4 & 4.4 & 5 & 1.3 & 5 \\
\hline Betamethasone & 3 & 3.3 & 6 & 2.0 & 11 \\
\hline Phytomenadione & 3 & 3.3 & 3 & - & - \\
\hline Beclometasone & 3 & 3.3 & 4 & 1.3 & 3 \\
\hline Captopril & 3 & 3.3 & 6 & 2.0 & 11 \\
\hline Erythromycin & 3 & 3.3 & 4 & 1.3 & 10 \\
\hline
\end{tabular}

Birth weight $>1000 \mathrm{~g}$ and $\leq 1500 \mathrm{~g}$; frequency $>2$; ${ }^{\text {a }}$ drugs with potential renal side effects [2] 
Table 4 Differences between active substances use among groups for the main drug classes

\begin{tabular}{|c|c|c|c|c|c|c|}
\hline & GROUP A \% $(N=68)$ & GROUP B \% $(N=91)$ & $p$ & $\begin{array}{l}\text { GROUP A overall } \\
\text { exposure, } d\end{array}$ & $\begin{array}{l}\text { GROUP B overall } \\
\text { exposure, } d\end{array}$ & $p$ \\
\hline ANTIBACTERIALS FOR SYSTEMIC USE & 100,0 & 91.2 & .07 & 48 & 14 & \\
\hline Ampicillin ${ }^{a}$ & 97.1 & 87.5 & .07 & 7 & 5 & .16 \\
\hline Amikacin $^{a}$ & 97.1 & 35.2 & $<.0001$ & 7 & 4 & .33 \\
\hline Piperacillin and enzyme inhibitor ${ }^{\mathrm{a}}$ & 47.1 & 12.1 & $<.0001$ & 13 & 11 & .03 \\
\hline Metronidazole & 39.7 & 7.7 & $<.0001$ & 13 & 9 & .10 \\
\hline Vancomycin ${ }^{a}$ & 35.3 & 14.3 & $<.0001$ & 13 & 13 & .01 \\
\hline Clarithromycin & 29.4 & 5.5 & $<.0001$ & 15 & 13 & .02 \\
\hline Erythromycin ethylsuccinate & 19.1 & 2.2 & $<.0001$ & 15 & 8 & .25 \\
\hline ANTIMYCOTICS FOR SYSTEMIC USE & 92.6 & 49.5 & $<.0001$ & 36 & 18 & \\
\hline Fluconazole & 92.6 & 49.5 & $<.0001$ & 32 & 18 & .78 \\
\hline Amphotericin $\mathrm{B}^{\mathrm{a}}$ & 13.2 & 1.1 & .03 & 20 & 1 & .01 \\
\hline RESPIRATORY SYSTEM PRODUCTS & 55.9 & 39.6 & .02 & 7 & 3 & \\
\hline Lung surfactant - natural phospholipidis & 45.6 & 37.4 & .69 & 3 & 1 & .85 \\
\hline Doxapram & 17.6 & 6.6 & .21 & 15 & 14 & .32 \\
\hline Caffeine & 95.6 & 75.8 & .02 & 45 & 27 & n.a. \\
\hline DIURETICS & 83.8 & 31.9 & $<.0001$ & 65 & 26 & \\
\hline Furosemide ${ }^{a}$ & 72.1 & 25.3 & .77 & 12 & 11 & .08 \\
\hline Hydrochlorothiazide & 50,0 & 8.8 & .07 & 46 & 26 & .31 \\
\hline Spironolactone & 50,0 & 8.8 & .07 & 46 & 26 & .31 \\
\hline CARDIAC THERAPY & 55.9 & 28.6 & $<.0001$ & 23 & 9 & \\
\hline Dopamine & 44.1 & 12.1 & .10 & 12 & 7 & .52 \\
\hline Dobutamine & 36.8 & 5.5 & .02 & 7 & 11 & .02 \\
\hline Ibuprofen ${ }^{a}$ & 32.4 & 12.1 & .43 & 2 & 2 & .37 \\
\hline
\end{tabular}

GROUP A: birth weight $\leq 1000 \mathrm{~g}$; GROUP B: birth weight $>1000 \mathrm{~g}$ and $\leq 1500 \mathrm{~g}$; ${ }^{\text {adrugs }}$ with potential renal side effects [2]

with nephrotoxic potential, such as aminoglycosides and diuretics, is recognized $[25,26]$.

Moreover, recent evidence on aminoglycoside use in preterm neonates and kidney damage shows that amikacin seems to be safer than gentamicin [27].

Our findings on combination of drugs with potential nephrotoxicity showed that the combinations of two different antibacterial agents and an antibacterial with furosemide were frequently reported in preterm neonates, though for short periods. The benefit-risk profile of combination of drugs in preterm neonates remains almost unexplored. To the best of our knowledge, only one study assessed the clinical consequences of the use of one aminoglycoside and furosemide in combination in the neonatal intensive care setting, showing that cycles longer than 4.5 days were associated with increased risk of acute kidney injury [28]. In our population, this combination did not exceed 2 days, thus minimizing this concern.

Factors that can aggravate kidney damage are prematurity, diet and concomitant disorders, for instance, perinatal

Table 5 Most commonly reported associations of drugs with potential renal side effects [2]

\begin{tabular}{lllll}
\hline & & GROUP A & & GROUP B \\
& $\%(N=68)$ & Duration per course, average & $\%(N=91)$ & Duration per course, average \\
\hline Ampicillin, Amikacin & 94,1 & 1,5 & 31,9 & 1,4 \\
Piperacillin, Vancomycin & 32,4 & 1,9 & 9,9 & 2,5 \\
Amikacin, Furosemide & 20,6 & 1,6 & 7,7 & 1,3 \\
Ampicillin, Furosemide & 19,1 & 1,1 & 15,4 & 1,6 \\
Amikacin, Acetaminophen & 5,9 & 1,5 & 2,2 & 1,2 \\
Amikacin, Amphotericin B & 2,9 & 1,7 & - & - \\
\hline
\end{tabular}

GROUP A: birth weight $\leq 1000 \mathrm{~g}$; GROUP B: birth weight $>1000 \mathrm{~g}$ and $\leq 1500 \mathrm{~g}$ 
Table 6 Characteristics of protein administration (as part of parenteral nutrition) among groups

\begin{tabular}{lccc}
\hline & GROUP A (N=69) & GROUP B (N=91) & $p$ \\
\hline $\begin{array}{l}\text { Patients receiving } \\
\text { protein supplement, } \%\end{array}$ & 98.5 & 91.2 & \\
Average dosage, g/kg & 2.36 & 2.11 & .83 \\
min dosage, g/kg & 0.5 & 0.5 & \\
max dosage, g/kg & 3.75 & 3.5 & \\
Overall exposure (on & 35 & 17 & .01 \\
average), days & & & \\
min, days & 1 & 1 & \\
max, days & 111 & 61 & \\
Combination with & & & \\
drugs, \% & & 33.3 & $<.0001$ \\
ampicillin, amikacin & 85.3 & 80.8 & .97 \\
ampicillin & 66.2 & 11.5 & $<.0001$ \\
furosemide & 44.1 & 16.7 & .03 \\
piperacillin & 29.4 & 7.7 & $<.0001$ \\
piperacillin, vancomycin & 26.5 & & \\
\hline GROuP A: birth weight $\leq 1000 \mathrm{~g}:$ GROUP B: birth weight $>1000 \mathrm{~g}$ and $\leq 1500 \mathrm{~g}$ &
\end{tabular}

asphyxia, respiratory distress syndrome and sepsis [29-32], whereas the effect of protein intake on renal function in the preterm population is still to be clearly characterized. Nutritional supply is essential for the prevention of growth failure of premature babies: insufficient energy and macronutrients intake may lead to unbalanced growth, altered neurological development and increased risk of morbidity [33].

Some limitations of this study should be acknowledged to better interpret our findings: the study was conducted in a single Italian university hospital, which may limit the generalizability of our findings to other settings; also, the amount of protein intake here described did not take into account enteral nutrition, resulting in underestimation of the total amount of protein intake.

\section{Conclusions}

With this retrospective study we presented an accurate description of pattern of drug use in an Italian NICU and, by using a novel approach, we further described the combination of active substances. Neonates born prematurely, especially ELBW, received a number of different pharmacological treatments from the first day after birth and in several cases drugs were administered in combination. Most of the drugs used in combination have potential renal side effects (e.g. amikacin and ampicillin), but they were administered for short periods. For most of those drugs, the riskbenefit profile is still not fully assessed in the neonatal population, and scanty evidence is available for their use in combination. Further studies, involving more than one Centre, should explore the safety of the most used combinations of drugs in NICU patients, such as aminoglycosides and furosemide, with special attention to renal toxicity.

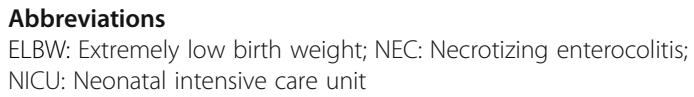

Availability of data and materials

The data will not be shared to respect the privacy of participants.

\section{Authors' contributions}

AG designed the study, collected and analyzed the data, wrote the first draft. SG designed the study, contributed to interpretation of data and revised the manuscript. AK performed the statistical analyses and revised the manuscript. ER, EP and FDP contributed to interpretation of data, revised the manuscript and made substantial scientific contributions. GF revised the manuscript. All authors approved the final manuscript as submitted.

\section{Competing interests}

The authors declare that they have no competing interests.

\section{Consent for publication}

Not applicable.

Ethics approval and consent to participate

The study was notified to the Institutional Ethics Committee (Comitato Etico Policlinico S. Orsola-Malpighi, 34/2015/U/Oss).

\section{Publisher's Note}

Springer Nature remains neutral with regard to jurisdictional claims in published maps and institutional affiliations.

Received: 13 December 2016 Accepted: 30 March 2017 Published online: 17 April 2017

\section{References}

1. Guideline on the investigation of medicinal products in the term and preterm neonate. Committee for Medicinal Products for Human Use and Paediatric Committee. http://www.ema.europa.eu/docs/en_GB/document_ library/Scientific_guideline/2009/09/WC500003750.pdf.

2. Girardi A, Raschi E, Galletti S, Poluzzi E, Faldella G, Allegaert K, De Ponti F. Drug-induced renal damage in preterm neonates: state of the art and methods for early detection. Drug Saf. 2015;38:535-51.

3. Cuzzolin L, Agostino R. Off-label and unlicensed drug treatments in Neonatal Intensive Care Units: an Italian multicentre study. Eur J Clin Pharmacol. 2016;72(1):117-23.

4. Conroy S, Mclntyre J. The use of unlicensed and off-label medicines in the neonate. Semin Fetal Neonatal Med. 2005;10:115-22.

5. Krzyzaniak N, Pawlowska I, Bajorek B. Review of drug utilization patterns in NICUs worldwide. J Clin. Pharm. Ther. 2016;41(6):612-20.

6. European Medicines Agency decision - PDCO Meeting June 201586. European Medicines Agency (EMA). http://www.ema.europa.eu/docs/en_ GB/document_library/Other/2015/07/WC500190385.pdf.

7. Marchant EA, Boyce GK, Sadarangani M, Lavoie PM. Neonatal sepsis due to coagulase-negative staphylococci. Clin Dev Immunol. 2013;2013:586076.

8. Manzoni P, Rizzollo S, Decembrino L, Ruffinazzi G, Rossi RA, Gallo E, Stolfi I, Mostert M, Stronati M, Farina D. Recent advances in prevention of sepsis in the premature neonates in NICU. Early Hum Dev. 2011;87 Suppl 1:S31-3.

9. Mitha A, Foix-L'Helias L, Arnaud C, Marret S, Vieux R, Aujard Y, Thiriez G, Larroque B, Cambonie G, Burguet A, Boileau P, Roze JC, Kaminski M, Truffert 
P, Ancel PY. Neonatal infection and 5-year neurodevelopmental outcome of very preterm infants. Pediatrics. 2013;132:e372-80.

10. Clark RH, Bloom BT, Spitzer AR, Gerstmann DR. Reported medication use in the neonatal intensive care unit: data from a large national data set. Pediatrics. 2006;117:1979-87.

11. Neubert A, Lukas K, Leis T, Dormann H, Brune K, Rascher W. Drug utilisation on a preterm and neonatal intensive care unit in Germany: a prospective, cohort-based analysis. Eur J Clin Pharmacol. 2010;66:87-95.

12. Goncalves AC, Reis AM, Gusmao AC, Bouzada MC. Drug utilisation profile in the neonatal unit of a university hospital: a prospective observational study in Brazil. Int J Clin. Pharm. 2015;37(4):645-55.

13. Laforgia N, Nuccio MM, Schettini F, Dell'aera M, Gasbarro AR, Dell'erba A, Solarino B. Off-label and unlicensed drug use among neonatal intensive care units in Southern Italy. Pediatr Int. 2014;56:57-9.

14. Haslund-Krog S, Mathiasen R, Christensen HR, Holst H. The impact of legislation on drug substances used off-label in paediatric wards-a nationwide study. Eur J Clin Pharmacol. 2014;70:445-52.

15. Kieran EA, O'Callaghan N, O'Donnell CP. Unlicensed and off-label drug use in an lrish neonatal intensive care unit: a prospective cohort study. Acta Paediatr. 2014;103:e139-42.

16. Leroux S, Zhao W, Betremieux P, Pladys P, Saliba E, Jacqz-Aigrain E. Therapeutic guidelines for prescribing antibiotics in neonates should be evidence-based: a French national survey. Arch Dis Child. 2015;100:394-8.

17. Schulman J, Dimand RJ, Lee HC, Duenas GV, Bennett MV, Gould JB. Neonatal intensive care unit antibiotic use. Pediatrics. 2015;135:826-33.

18. Soll RF, Edwards WH. Antibiotic use in neonatal intensive care. Pediatrics 2015;135:928-9.

19. Kaufman D, Boyle R, Hazen KC, Patrie JT, Robinson M, Donowitz LG. Fluconazole prophylaxis against fungal colonization and infection in preterm infants. N Engl J Med. 2001;345:1660-6.

20. Manzoni P, Stolfi I, Pugni L, Decembrino L, Magnani C, Vetrano G, Tridapalli E, Corona G, Giovannozzi C, Farina D, Arisio R, Merletti F, Maule M, Mosca F, Pedicino R, Stronati M, Mostert M, Gomirato G. A multicenter, randomized trial of prophylactic fluconazole in preterm neonates. N Engl I Med. 2007; 356:2483-95.

21. Kaguelidou F, Pandolfini C, Manzoni P, Choonara I, Bonati M, Jacqz-Aigrain E. European survey on the use of prophylactic fluconazole in neonatal intensive care units. Eur J Pediatr. 2012;171:439-45.

22. Pandolfini C, Marco S, Paolo M, Maurizio B. The use of ciprofloxacin and fluconazole in Italian neonatal intensive care units: a nationwide survey. BMC Pediatr. 2013;13:5.

23. Askenazi DJ, Koralkar R, Hundley HE, Montesanti A, Patil N, Ambalavanan N. Fluid overload and mortality are associated with acute kidney injury in sick near-term/term neonate. Pediatr Nephrol. 2013;28:661-6.

24. Koralkar R, Ambalavanan N, Levitan EB, McGwin G, Goldstein S, Askenazi D. Acute kidney injury reduces survival in very low birth weight infants. Pediatr Res. 2011:69:354-8

25. Taber SS, Pasko DA. The epidemiology of drug-induced disorders: the kidney. Expert Opin Drug Saf. 2008;7:679-90

26. Pacifici GM. Clinical pharmacology of furosemide in neonates: a review. Pharmaceuticals (Basel). 2013;6:1094-129.

27. Vieux R, Fresson J, Guillemin F, Hascoet JM. Perinatal drug exposure and renal function in very preterm infants. Arch Dis Child Fetal Neonatal Ed. 2011;96:F290-5.

28. Safina Al, Daminova MA, Abdullina GA. Acute kidney injury in neonatal intensive care: Medicines involved. Int J Risk Saf Med. 2015;27 Suppl 1:S9-S10

29. Elmas AT, Tabel $Y$, Elmas ON. Serum cystatin $C$ predicts acute kidney injury in preterm neonates with respiratory distress syndrome. Pediatr Nephrol. 2013;28:477-84

30. Kandasamy $Y$, Smith $R$, Wright IM. Measuring cystatin $C$ to determine renal function in neonates. Pediatr Crit Care Med. 2013;14:318-22.

31. Sarafidis K, Tsepkentzi E, Agakidou E, Diamanti E, Taparkou A, Soubasi V, Papachristou F, Drossou V. Serum and urine acute kidney injury biomarkers in asphyxiated neonates. Pediatr Nephrol. 2012;27:1575-82.

32. Walker MW, Clark RH, Spitzer AR. Elevation in plasma creatinine and renal failure in premature neonates without major anomalies: terminology, occurrence and factors associated with increased risk. J Perinatol. 2011;31:199-205.

33. Stoltz SE, Ohlund I, Ahlsson F, Engstrom E, Fellman V, Hellstrom A, Kallen K, Norman M, Olhager E, Serenius F, Domellof M. Nutrient intakes independently affect growth in extremely preterm infants: results from a population-based study. Acta Paediatr. 2013;102:1067-74.

\section{Submit your next manuscript to BioMed Central and we will help you at every step:}

- We accept pre-submission inquiries

- Our selector tool helps you to find the most relevant journal

- We provide round the clock customer support

- Convenient online submission

- Thorough peer review

- Inclusion in PubMed and all major indexing services

- Maximum visibility for your research

Submit your manuscript at www.biomedcentral.com/submit
C Biomed Central 